\title{
BMJ Open Fatty liver index as a predictor of increased risk of cardiometabolic disease: finding from the Kuopio Ischaemic Heart Disease Risk Factor Study Cohort
}

Olubunmi O. Olubamwo, ${ }^{1}$ Jyrki K. Virtanen, ${ }^{1}$ Jussi Pihlajamaki, ${ }^{1,2}$ Pekka Mantyselka, ${ }^{1,3}$ Tomi-Pekka Tuomainen ${ }^{1}$

To cite: Olubamwo 00 , Virtanen JK, Pihlajamaki J, et al. Fatty liver index as a predictor of increased risk of cardiometabolic disease: finding from the Kuopio Ischaemic Heart Disease Risk Factor Study Cohort. BMJ Open 2019;9:e031420. doi:10.1136/ bmjopen-2019-031420

- Prepublication history and additional material for this paper are available online. To view these files, please visit the journal online (http://dx.doi org/10.1136bmjopen-2019031420).

Received 07 May 2019 Revised 09 August 2019 Accepted 12 August 2019

Check for updates

(c) Author(s) (or their employer(s)) 2019. Re-use permitted under CC BY-NC. No commercial re-use. See rights and permissions. Published by BMJ.

${ }^{1}$ Institute of Public Health and Clinical Nutrition, Faculty of Health Sciences, University of Eastern Finland, Kuopio, Finland ${ }^{2}$ Clinical Nutrition and Obesity Center, Kuopio University Hospital, KYS, Kuopio, Finland

${ }^{3}$ Primary Health Care Unit, Kuopio University Hospital, Kuopio, Finland

Correspondence to Dr Olubunmi 0. Olubamwo; olubunmi.olubamwo@uef.fi

\section{ABSTRACT}

Objective Fatty liver disease (FLD), a global epidemic, is also a predictor of cardiometabolic disease (CMD) (type 2 diabetes or cardiovascular disease). Our objective was to examine whether progressive FLD, as assessed by fatty liver index (FLI), predicts increasing future CMD risk compared with relatively stable FLD, among middle-aged men.

Design Prospective epidemiological study.

Setting University affiliated research centre in Kuopio, Eastern Finland.

Participants Our subjects were 501 men without CMD during the initial 4-year follow-up in the Kuopio Ischaemic Heart Disease Risk Factor Study cohort.

Outcome measure Over the initial 4-year follow-up, 135 men $(26.9 \%)$ had a significant $(\geq 10)$ FLI increase. The association of 4-year FLI increase with incident CMD was analysed in multivariable-adjusted Cox regression models, adjusting for baseline constitutional and lifestyle factors (model 1) and, in addition, metabolic and inflammation biomarker factors (model 2).

Results During a mean follow-up of 15 years, 301 new CMD cases occurred. We used subjects with low baseline FLI and no significant 4-year FLI increase as the reference. For subjects with intermediate baseline FLI and significant 4-year FLI increase, the HRs and 95\% Cls for incident CMD in model 1 (2.13 (1.45 to 3.13)) and model 2 (1.73 (1.13 to 2.66)) exceeded values for subjects with similar baseline FLI without a significant 4-year change (HRs $(95 \% \mathrm{Cls})$ were 1.36 ( 0.94 to 1.97$)$ for model 1 and $1.18(0.81$ to 1.70) for model 2). They approached $\mathrm{HRs}(95 \% \mathrm{Cl})$ for subjects who maintained high FLI over the 4 years (HRs (95\% Cls) were 2.18 (1.54 to 3.10 ) in model 1 and 1.85 (1.21 to 2.82) in model 2).

Conclusion Persons with significant FLI increase are likely with increasing CMD risk. Such persons should be evaluated for progressive FLD and CMD and managed to reduce CMD risk.

\section{INTRODUCTION}

Fatty liver disease (FLD) has become a global epidemic. Although the incidence of FLD varies widely, the current global prevalence is

\section{Strengths and limitations of this study}

- The study is population-based with a prospective design and a long follow-up.

- Our statistical models were adjusted for a range of constitutional factors, lifestyle factors and metabolic and inflammation biomarkers.

- Categorisation according to fatty liver index changes allowed clear comparison of cardiometabolic disease risk between change categories.

- The study population comprised men only.

- The statuses of the men with respect to viral hepatitis were not established at baseline, although the prevalence of viral hepatitis has remained low in the Finnish population.

estimated to be over 25\%. ${ }^{1}$ Despite the rising incidence and prevalence, primary-care record studies and the limited data available from vital registries indicate that there is significant underdiagnosing and under-reporting of the condition. ${ }^{23}$ FLD is a heterogeneous disease. Although it is classified broadly into to alcoholic fatty liver disease (AFLD) and non-alcoholic fatty liver disease (NAFLD), it comprises a spectrum of histological features, including simple steatosis, acute hepatitis and cirrhosis. ${ }^{45}$

Recent studies on NAFLD indicate that hepatic lipid accumulation, particularly saturated free fatty acids and free cholesterol, can promote lipotoxicity and mitochondrial dysfunction, resulting in hepatocyte apoptosis, inflammation and fibrosis. Thus, FLD can progress from steatosis to steatohepatitis, fibrosis and cirrhosis. ${ }^{6}$ The natural course, however, is variable. NAFLD patients without steatohepatitis may also develop progressive fibrosis. ${ }^{7}$ The presence of fibrosis has been recognised as the strongest marker of 
severity, ${ }^{8}$ and it can occur in both NAFL and NASH. ${ }^{9}$ In recent years, attention has been drawn to the fact that progression of FLD, including AFLD and NAFLD, is also associated with risk of long-term extrahepatic cardiometabolic disease (CMD) outcomes. ${ }^{10-12}$ Meta-analyses of studies on NAFLD show that the NAFLD is associated with significant increase in risks of type 2 diabetes (T2D), CVD and CVD events. ${ }^{13}{ }^{14}$ Similarly, the fibrosis stage has been recognised as a predictor of incident cardiovascular events. $^{8}$

Evidence on the rising global prevalence of FLD and its hepatic and CMD outcomes, highlight the need for public health initiatives, together with basic and clinical research, aimed ultimately at controlling FLD and its outcomes. ${ }^{15} 16$ Fatty liver is reversible and amenable to treatment and intervention can prevent progression. ${ }^{17-19}$ It is logical, therefore, to deduce that such intervention can prevent further increase in the risk of incident CMD. However, the effect of FLD progression on the risk of incident CMD is less studied, to the effect that there is paucity of comparative studies of the association of progressive hepatic steatosis with increased cardiometabolic risk. CMDs (T2D and CVD) are leading causes of mortality and are largely preventable, potentially also through intervention resulting from early detection of occurrence and progression of FLDs. ${ }^{20} 21$

One major challenge militating against the study of the consequences of progressive FLD on the risk of CMD is the need for repeated liver assessment. Liver biopsy and MRI are expensive. The fatty liver index (FLI), an algorithm which was developed by Bedogni $e t a l$, is also easy to employ, being derived from routine tests and measurements. It had an accuracy of $0.84(95 \%$ CI 0.81 to 0.87$)$ in detecting fatty liver. ${ }^{22}$ Therefore, it can provide informative indication regarding metabolic derangements, associated liver histology and need for further evaluation. For example, it can identify patients who need radiological evaluation. ${ }^{23}$ A significant increase in FLI suggests either a development of new FLD or a progression of existing FLD. ${ }^{24}$

The development of NAFLD and fibrosis depends on metabolic factors that occur at an increased frequency with advancing age, ${ }^{25}$ and this may have a bearing on the risk of CMDs. The observation in the Kuopio Ischaemic Heart Disease Risk Factor Study (KIHD) cohort is that, for a significant proportion of the subjects, the FLIs increased by the $11^{\text {th }}$ year of follow-up. ${ }^{26}$ The objective of our study was to determine whether progression of FLD, as assessed by significant increase in FLI, is associated with increased risk of future CMD when compared with the corresponding stable status. Although, high FLI has been shown to identify people at risk of incident CMDs. ${ }^{26}{ }^{27}$ The risk of incident CMDs in relation to FLI changes has not been documented. It is expected that among subjects with similar baseline FLI values, a significant increase in FLI is associated with greater risk of incident CMD compared with stable FLI. This study will provide further justification in the monitoring of people for increased risk.

\section{METHODS}

\section{Study population}

Our study population comprised participants in the KIHD. The KIHD study is a prospective population-based study designed to investigate risk factors for CVDs and related outcomes in middle-aged and ageing men from Eastern Finland. The original study population consisted of an age-stratified sample of $2682 \mathrm{men}$. These were enrolled at baseline between March 1984 and December 1989. The men were $42,48,54$ or 60 years of age at baseline. ${ }^{28}$

\section{Data collection}

Data were collected through self-administered questionnaires, interviews, physical examinations and various blood tests to determine physiological and biochemical parameters. $^{29}{ }^{30}$ The self-administered questionnaires were used to collect data on medical history, including history of T2D, CVD, metabolic diseases, liver disease and other chronic diseases, medication history, family history of diabetes and family history of CVD. ${ }^{29}$ Data on lifestyle factors, including physical activity, smoking habit, alcohol consumption and diet, were also collected. ${ }^{31}$ Categorisation of alcohol consumption was done according to standard guidelines by the National Institute of Alcohol Abuse and Alcoholism ${ }^{32}$ and Dietary Guidelines for Americans $2010 .{ }^{33}$ Fruit, berry and vegetable consumption was calculated as the mean consumption over 4 days in gram. ${ }^{34} 35$

Physical examinations included anthropometric indices, vital signs and physiologic measurements. Waist circumference was calculated as the mean of waist circumferences taken at maximal inspiration and maximal expiration. Body mass index (BMI) was calculated as the ratio of weight in kilogram to the square of height in metre $\left(\mathrm{kg} / \mathrm{m}^{2}\right)$. Blood pressure (BP) was taken as the mean of measurements in supine, standing and sitting positions with 5 min intervals. ${ }^{35}$

Blood samples were collected between 8 and 10 hours after 3 days of abstinence from alcohol consumption and 12 hours abstinence from smoking and eating. These were processed using standard methods. Data on complete blood count; serum electrolytes; homeostatic model assessment of insulin resistance; fasting glucose; lipoprotein fractions (including total cholesterol, high-density lipoprotein cholesterol (HDLc), low-density lipoprotein cholesterol (LDLc) and serum triglycerides); liver function tests, including albumin, gamma-glutamyl transferase (GGT), fibrinogen and ferritin; and biomarkers like $\mathrm{C}$ reactive protein (CRP) were each determined from the appropriate samples. ${ }^{28}$ A subject was categorised as having metabolic syndrome, according to the harmonised criteria, if at least three of the following alterations were present: waist circumference $\geq 94 \mathrm{~cm}$, serum triglycerides $\geq 1.70 \mathrm{mmol} / \mathrm{L}$ or specific treatment for hypertriglyceridemia, serum HDLc $<1.03 \mathrm{mmol} / \mathrm{L}$, systolic BP $\geq 130 \mathrm{~mm}$ $\mathrm{Hg}$ or diastolic $\mathrm{BP} \geq 85 \mathrm{~mm} \mathrm{Hg}$ or treatment for previously diagnosed hypertension, and fasting plasma glucose $\geq 5.6$ $\mathrm{mmol} / \mathrm{L}^{36}$ 
Subjects recruited at baseline $n=2682$

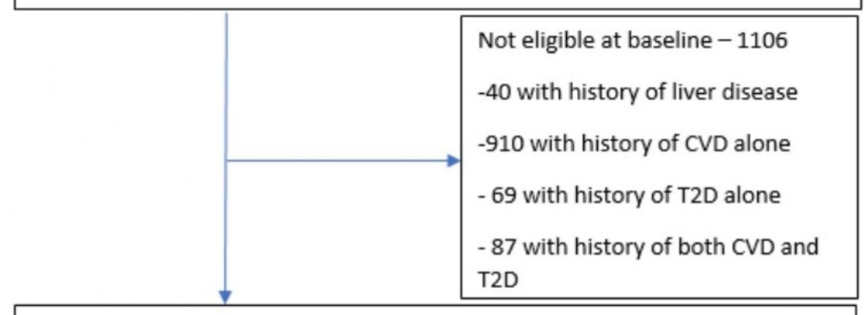

Subjects without history of liver disease, CVD or T2D at baseline $n=1576$

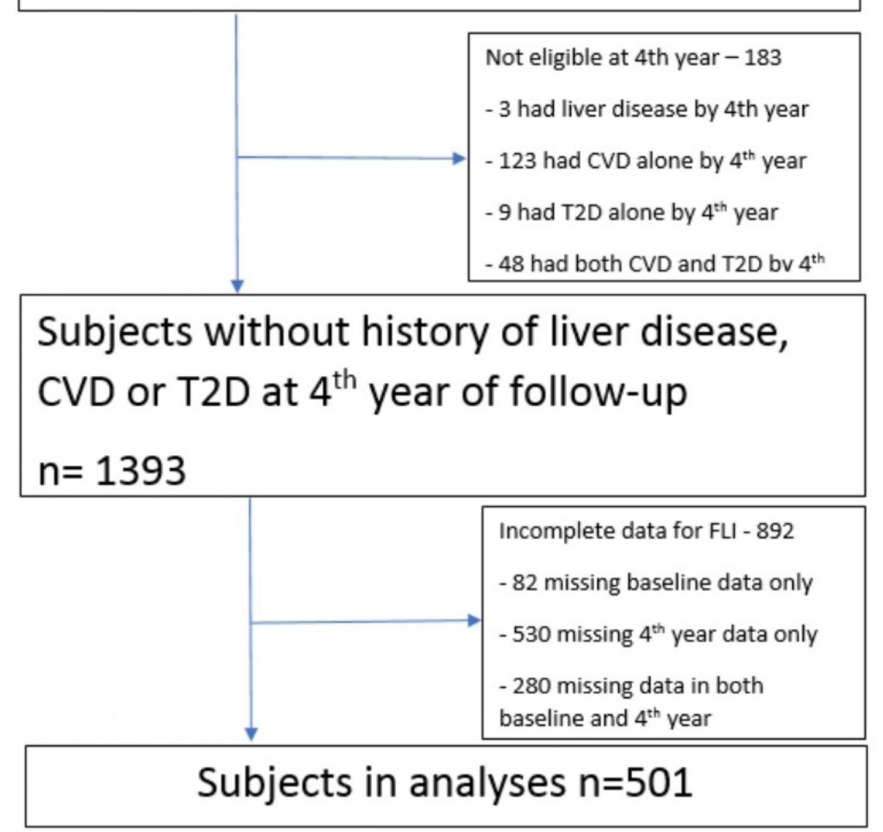

Figure 1 Flowchart depicting the selection of study participants. CVD, cardiovascular disease; FLI, fatty liver index; T2D, type two diabetes.

\section{Included and excluded subjects}

The selection of subjects is illustrated in figure 1 . The initial number of subjects at baseline was 2682. After excluding 1289 subjects with either liver disease or CMD, 501 subjects had complete data for calculating both baseline and fourth-year FLI. These were eligible for the study.

\section{Measuring the components of the FLI}

We calculated baseline and fourth-year FLI using the algorithm developed by Bedogni et al. ${ }^{22}$ The component variables of the algorithm are BMI, waist circumference, triglycerides and GGT. These are routine measurements in clinical practice. An FLI $<30$ ruled out and an FLI $\geq 60$ ruled in hepatic steatosis as detected by ultrasonography. The algorithm is expressed as follows:

$$
\mathrm{FLI}=\frac{\left(\mathrm{e}^{0.953 \times \ln (\text { triglycerides })+0.139 \times \mathrm{BMI}+0.718 \times \ln (\mathrm{GGT})}\right)}{\left(1+\mathrm{e}^{0.953 \times \ln (\mathrm{GGT})+0.053 \times \text { waist circumference }-15.745}\right)} \times 100
$$

where triglycerides is in $\mathrm{mg} / \mathrm{dL}, \mathrm{GGT}$ : $\gamma$-glutamyl transferase in $\mathrm{U} / \mathrm{L}$ : waist circumference is in $\mathrm{cm}$, and $\mathrm{BMI}$ is in $\mathrm{kg} / \mathrm{m}^{2}$. In agreement with Bedogni et $a l^{22}$ we categorised FLI as low, intermediate and moderate-high.

\section{Change in FLI and category of change in FLI}

Longitudinal (4-year) changes in FLIs were computed by comparison of FLIs at the end of the fourth year, with the baseline FLIs. A change in FLI was defined as baseline FLI \pm 10 FLI units at the fourth year. FLI change direction was categorised as decrease (baseline FLI minus $\geq 10$ FLI units at fourth year), no change (baseline FLI $\pm<10$ FLI units at fourth year) or increase (baseline FLI $+\geq 10$ FLI units at fourth year). A change in FLI was considered significant if it also resulted in a change in FLI category from the baseline category. The changes in FLI were thus categorised according to magnitude, direction and significance. The resulting change categories were

- Category 1 (reference): - baseline FLI in low category with no significant increase over the 4 years.

- Category 2: baseline FLI in low category and significant increase over the 4 years.

- Category 3: - baseline FLI in intermediate category and significant decrease over the 4 years.

- Category 4: baseline FLI in intermediate category and no significant change over the 4 years.

- Category 5: baseline FLI in intermediate category and significant increase over 4 years.

- Category 6: baseline FLI in high category and significant decrease over 4 years.

- Category 7: baseline FLI in high category and no significant decrease over 4 years.

The development of CMD during the follow-up period in relation to the 4-year FLI change categories was studied to determine the association of FLI category with the risk of CMD.

\section{Outcome definitions}

The incident CMDs were cases with either CVD or T2D or both. We included only first disease diagnoses that occurred between the end of fourth-year examinations and 32 December 2012. Incident episodes of CVD and outcomes were collected by record linkage to the national care register for healthcare data on inpatient care (Hoitoilmoitusjärjestelmä), controlled by the National Institute for Health and Welfare. These include angina pectoris, acute myocardial infarction, chronic ischaemic heart disease, cerebrovascular diseases, vascular diseases and others as coded in the 10th Revision of the International Classification of Diseases (ICD 10) code numbers I00-I99. We defined incident T2D outcomes as self-reported physician-set diagnosis of T2D and/or fasting plasma glucose $\geq 7.0 \mathrm{mmol} / \mathrm{L}$ or 2-hour oral glucose tolerance test plasma glucose $\geq 11.1 \mathrm{mmol} / \mathrm{L}$, at re-examination rounds 4, 11 and 20 years after the baseline, and, by record linkage, to the national hospital discharge register and to the Social Insurance Institution of Finland register 
for reimbursement of medicine expenses used for T2D. Detection of T2D by self-report of physician diagnosis was followed by either detection via the hospital discharge registers or detection via the National drug reimbursement register. T2D cases that were included were those coded in the ICD 10 code numbers from E11.0 to E11.9.

\section{Patient and public involvement}

The study was carried out at a university affiliated research facility. All the study participants were volunteers. Neither the study participants nor the public were involved in the design of the study.

\section{Statistical analyses}

All statistical analyses were performed using Statistical Package for the Social Sciences (SPSS) software V.24.0 for Windows (IBM, Chicago, IL, USA). Descriptive analyses were performed to summarise baseline characteristics of participants according to baseline FLI categories (tables 1 and 2). We used Jonckheere trend test to test for linear trend across FLI categories of continuous variables. We used $\chi^{2}$ test to test for linear association across FLI categories of categorical variables. We used a regression-based multiple imputation method (40 iterations) to make up for missing $3.2 \%$ values (spread across $39 \%$ of the variables and $100 \%$ of subjects), according to guideline by Cheema. ${ }^{37}$

We used multivariable adjusted Cox regression models with progressive degrees of adjustments to analyse the association between 4-year FLI change categories and occurrence of incident CMD, expressed as HR. The models were as follows: in model 1, we adjusted for constitutional factors (examination year and age at baseline) and lifestyle factors (smoking pack-years, alcohol consumption, physical activity, and consumption of fruits, berries and vegetables). In model 2, we adjusted for variables in model 1 and metabolic factors (fasting glucose, insulin, high-density lipoprotein, low-density lipoprotein, systolic BP and diastolic BP) and inflammatory markers (CRP, leucocyte count and thrombocyte count). Two-sided alpha $<0.05$ was considered statistically significant.

In subanalyses, we excluded men with a high weekly alcohol consumption $(\geq 168 \mathrm{~g})^{38}$ to observe if the associations differ when heavy alcohol consumers are excluded in the analyses. In sensitivity analyses, we analysed our data for the association censoring at 14 years from baseline (ie, 10 years after change was observed). We also analysed our data using CVD and T2D as separate outcomes.

\section{RESULTS}

\section{Characteristics of the study population}

The baseline characteristics of the study population (501 men) according to their baseline FLI categories are shown in table 1 . There was no significant difference in the constitutional factors across the FLI categories. Of the lifestyle factors, the mean alcohol consumption was higher among men in the high FLI category than men in the low FLI category. For the anthropometrics and physiological measurements, and the biomarkers, a significant trend was observed across the FLI categories. Compared with the low FLI (reference) category, men in the high FLI category had higher mean waist circumference and mean BMI, and they were more likely to be hypertensive. They also had higher GGT levels, higher triglyceride, higher fasting insulin, higher blood glucose, lower HDLc and higher levels of markers of systemic inflammation. They were also likely to have metabolic syndrome.

Table 2 shows the fourth-year FLI and FLI change category of 501 men according to baseline FLI category. Over 4 years, 135 men $(27 \%)$ had a significant FLI increase (change category 2 plus change category 5 ). Eighty men who had low FLI at baseline had intermediate FLI by the fourth year (change category 2). Fifty-five men who had intermediate FLI at baseline had high FLI by the fourth year (change category 5 ).

\section{Multivariable Cox regression model analyses: relation between 4-year FLI increase category and incident CMD Overall analyses}

During a mean (SD) follow-up of 19.2 (5.5) years, there were 301 cases of incident CMD. The overall incidence rate for CMD in the 501 men was 36 cases per 1000 person-years. The proportion of events and incidence rate in each FLI category can be seen in table 3 .

We used subjects with low baseline FLI but no significant 4-year increase as the reference. Table 3 shows the association between FLI change categories with incident CMD. Subjects in change categories 2 and 5 had a significant FLI increase at the fourth year. For change category 2, the HR for incident CMD in model 1 was $48 \%$ higher than the reference. However, the difference was reduced to $36 \%$, and the association was no longer statistically significant in model 2 when we included metabolic and inflammatory factors. Notably, the HRs exceeded those of subjects in change category 4 . For the subjects in change category 5 , the HR for incident CMD in model 1 was $113 \%$ higher than the reference. Notably, the HR was $77 \%$ higher than the HR of those in change category 4 and approached the HR for those in category 7 . This difference was reduced to $55 \%$ in model 2, and the association maintained statistical significance when we included metabolic and inflammatory factors.

Subjects in change categories 3 and 6 had significant FLI decrease by the fourth year. Altogether, 24 (4.8\%) of the subjects who had either high FLI or intermediate FLI at baseline had significant decrease by the fourth year. As shown in model 2 of table 3 and, for change category 6 , the data suggest a tendency towards decreased risk when compared with subjects in change category 7 , who had similar FLIs at baseline (36\% lower in model 1 and 56\% lower in model 2). Also, among the change category 3 group, the data suggested decreased risk when compared with change category 4 , who also had an intermediate FLI category at baseline (8\% lower in model 1 but $2 \%$ decrease in model 2), but these were not statistically significant. 
Table 1 Baseline characteristics of 501 men according to FLI categories

\begin{tabular}{|c|c|c|c|c|}
\hline Characteristic & $\begin{array}{l}\text { FLI }<30 \\
\text { Mean (SD) or } n(\%) \\
n=253\end{array}$ & $\begin{array}{l}\text { FLl }=30-<60 \\
\text { Mean (SD) or } n(\%) \\
n=157\end{array}$ & $\begin{array}{l}\text { FLI } \geq 60 \\
\text { Mean (SD) or } n(\%) \\
n=91\end{array}$ & P trend* \\
\hline FLI & $15.3(7.8)$ & $42.6(8.4)$ & $75.0(10.1)$ & $<0.001$ \\
\hline \multicolumn{5}{|l|}{ Constitutional factors } \\
\hline Age in years & $50.5(6.5)$ & $52.2(6.9)$ & $49.1(6.3)$ & 0.966 \\
\hline Family history of diabetes & $66(26.1 \%)$ & $40(25.5 \%)$ & $23(25.3 \%)$ & 0.984 \\
\hline Family history of CVD & $201(79.4 \%)$ & $122(77.7 \%)$ & $77(84.6 \%)$ & 0.415 \\
\hline \multicolumn{5}{|l|}{ Lifestyle factors } \\
\hline Smoking pack-years & $7.7(15.6)$ & $9.1(17.6)$ & $7.2(12.9)$ & 0.696 \\
\hline Alcohol consumption (g/week) & 65 (110) & $71(92)$ & $138(169)$ & $<0.001$ \\
\hline $\begin{array}{l}\text { Physical activity (energy exp.) } \\
\text { (kcal/day) }\end{array}$ & 153(173) & $144(132)$ & 111(118) & 0.24 \\
\hline $\begin{array}{l}\text { Fruit, berry and vegetable } \\
\text { consumption (g/day) }\end{array}$ & $452(200)$ & $458(192)$ & $446(204)$ & 0.893 \\
\hline \multicolumn{5}{|c|}{ Anthropometrics and physiologic measurements } \\
\hline Mean waist circumference $(\mathrm{cm})$ & $82.9(5.8)$ & $91.6(5.3)$ & $99.9(7.6)$ & $<0.001$ \\
\hline $\mathrm{BMI}\left(\mathrm{kg} / \mathrm{m}^{2}\right)$ & $24.2(2.0)$ & $27.2(2.0)$ & $30.1(3.0)$ & $<0.001$ \\
\hline Mean systolic BP & $128.8(15.2)$ & $133.8(14.6)$ & $134.9(14.0)$ & $<0.001$ \\
\hline Mean diastolic BP & $84.5(9.6)$ & $88.8(8.8)$ & $91.9(9.0)$ & $<0.001$ \\
\hline Hypertension & $42(16.6 \%)$ & $43(27.4 \%)$ & $34(37.4 \%)$ & $<0.001$ \\
\hline \multicolumn{5}{|l|}{ Biomarkers } \\
\hline Insulin & $7.7(2.9)$ & $10.0(3.5)$ & $13.9(6.7)$ & $<0.001$ \\
\hline Glucose (mmol/L) & $4.4(0.5)$ & $4.6(0.4)$ & $4.7(0.5)$ & $<0.001$ \\
\hline HOMA1-IR insulin resistance & $1.72(0.67)$ & $2.33(0.83)$ & $3.28(1.82)$ & $<0.001$ \\
\hline Total cholesterol (mmol/L) & $5.58(1.07)$ & $5.80(0.82)$ & $6.11(0.89)$ & $<0.001$ \\
\hline HDLc (mmol/L) & $1.42(0.30)$ & $1.26(0.26)$ & $1.25(0.26)$ & $<0.001$ \\
\hline LDLc (mmol/L) & $3.75(1.02)$ & $3.95(0.79)$ & $4.08(0.84)$ & $<0.001$ \\
\hline Triglycerides (mmol/L) & $0.92(0.39)$ & $1.46(0.73)$ & $1.92(0.73)$ & $<0.001$ \\
\hline $\begin{array}{l}\text { Gamma-glutamyl transferase } \\
(\mathrm{U} / \mathrm{L})\end{array}$ & $18(10)$ & $27(20)$ & $51(45)$ & $<0.001$ \\
\hline Albumin & $42(4)$ & $43(4)$ & $43(4)$ & 0.080 \\
\hline C reactive protein (m/L) & $1.84(6.02)$ & $2.82(5.83)$ & $2.73(3.32)$ & $<0.001$ \\
\hline Ferritin ( $\mu \mathrm{g} / \mathrm{L})$ & $126(90)$ & $177(202)$ & $260(187)$ & $<0.001$ \\
\hline Fibrinogen g/L & $2.92(0.60)$ & $2.99(0.62)$ & $3.09(0.43)$ & $<0.001$ \\
\hline Leucocyte count $\times 10^{9} / \mathrm{L}$ & $5.4(1.6)$ & $5.7(1.5)$ & $5.8(1.9)$ & 0.002 \\
\hline \multicolumn{5}{|c|}{ Metabolic syndrome and medication use history } \\
\hline Metabolic syndrome & $7(2.6 \%)$ & $23(13.5 \%)$ & $58(54.2 \%)$ & $<0.001$ \\
\hline Drug for hypertension & $14(5.5 \%)$ & $16(10.2 \%)$ & $15(16.5 \%)$ & $<0.001$ \\
\hline
\end{tabular}

*Jonckheere trend test for continuous variable. $\chi^{2}$ linear-by-linear association for categorical variables.

BP, blood pressure; CVD, cardiovascular disease; FLI, fatty liver index; HDLc, high-density lipoprotein cholesterol; HOMA1-IR, homeostatic model assessment of insulin resistance; LDLc, low-density lipoprotein cholesterol.

\section{Subanalyses}

After exclusion of 68 men who were heavy alcohol consumers, the results were similar to those obtained in the main analyses, as shown in . Notably, for the subjects in change category 5 , the HR for incident CMD in model 1 was higher than the reference. In addition, the HR was
$78 \%$ higher than the HR of those in change category 4 and approached the HR for those in change category 7 .

Sensitivity analyses

When we analysed our data for the association censoring at 14 years from baseline (ie, 10 years after change was 
Table 2 Fourth-year FLI and FLI change category of 501 men according to baseline FLI category showing significant $\mathrm{FLI}$ increase in $135(27 \%)$ men

\begin{tabular}{|c|c|c|c|}
\hline $\begin{array}{l}\text { Fourth-year FLI } \\
\text { category or FLI } \\
\text { change category }\end{array}$ & $\begin{array}{l}\text { FLI<30 } \\
n(\%) \\
n=253\end{array}$ & $\begin{array}{l}\text { FLI=30- } \\
<60 \\
n(\%) \\
n=157\end{array}$ & $\begin{array}{l}\text { FLI } \geq 60 \\
n(\%) \\
n=91\end{array}$ \\
\hline Fourth-year FLI <30 & $166(65.6)$ & $20(12.7)$ & $1(1.1)$ \\
\hline $\begin{array}{l}\text { Fourth-year FLI=30- } \\
<60\end{array}$ & 79 (31.2) & $77(49.0)$ & $11(12.1)$ \\
\hline Fourth-year FLI $\geq 60$ & $8(3.2)$ & $60(38.2)$ & $79(86.8)$ \\
\hline 1 (Ref) & $173(68.4 \%)$ & - & - \\
\hline 2 & $80(31.6 \%)$ & - & - \\
\hline 3 & - & $14(8.9)$ & - \\
\hline 4 & - & $88(56.1)$ & - \\
\hline 5 & - & $55(35.0)$ & - \\
\hline 6 & - & - & $10(11.0)$ \\
\hline 7 & - & - & $81(89.0)$ \\
\hline
\end{tabular}

Change categories: 1, baseline FLI in low category with no significant FLI change in the fourth year; 2, baseline FLI in low category with significant FLI increase to category intermediate or high; 3, baseline FLI in intermediate category with significant FLI decrease to low category; 4, baseline FLI in intermediate category with no significant FLI change; 5, baseline FLI in intermediate category with significant FLI increase to high FLI category; 6 , baseline FLI in high category with significant decrease to intermediate or low category; 7 , baseline FLI in high category with no significant FLI decrease.

FLI, fatty liver index; Ref, reference.

observed), the results differed minimally from those obtained in the analyses after the entire follow-up. The difference was that the risk of CMD observed among those who progressed from normal (low) FLI at baseline was not statistically significant, as shown in table 4 . Results of the analyses with CVD and T2D as separate outcomes over the entire follow-up are shown in online supplementary tables 1 and 2 of the appendix. Subjects in change category 5 had $80 \%$ increase in CVD risk and $60 \%$ increase in T2D risk compared with change category 4. Subjects in change category 6 had T2D risk about $150 \%$ lower than those in change category 7 . A similar pattern was observed when high alcohol consumers were excluded.

\section{DISCUSSION}

Significant FLI increases, which occurred over the initial 4 years, resulted in a significant increase in the risk of CMD to a level comparable to that of subjects who maintained a higher FLI, at both baseline and at the fourth year. In addition, this increase in risk of CMD can be partly explained by metabolic and inflammatory factors. Although high FLI has been associated with CMDs, ${ }^{26}{ }^{27}$ this study shows that increase in FLI can identify people with increasing risk of CMDs.
The possible effect of progressive FLD on the association between FLD and cardiometabolic risk has been less studied. Sung et al found that development of new fatty liver was associated with increased risk of incident T2D. In their study, individuals in whom severity of fatty liver worsened over 5 years (from mild to moderate/severe) had a marked increase in the risk of incident T2D compared with individuals who had resolution of fatty liver. ${ }^{39}$

There is paucity of studies to elucidate why the risk of incident CMD is higher in subjects with progressive FLD than those with relatively stable disease. The attenuation of the association when metabolic and inflammatory factors were added to the models suggests that the higher risks observed in subjects with progressive disease can be explained by the interplay of metabolic and inflammatory factors. Progressive liver fat accumulation in patients with FLD is associated with increased rates of the metabolic syndrome, independent of steatohepatitis. ${ }^{40}$ For further increase in risk of incident T2D, it is thought that the initial development of insulin resistance results in compensatory hyperinsulinaemia and, together with visceral obesity, promotes the development of FLD. ${ }^{41}$ The insulin resistant fatty liver then overproduces glucose and very low-density lipoprotein. ${ }^{42}$ This boosts mechanisms that lead to exhaustion of pancreatic beta cell reserve. Steatotic and inflamed liver secretes hepatokines such as such as fetuin-A, fetuin-B, angiopoietin-like proteins, fibroblast growth factor 21 and selenoprotein $\mathrm{P}$, which have endocrine function at extrahepatic sites. These further promote insulin resistance and other adverse effects on glucose homeostasis. ${ }^{43}$ Eventually, this leads to further increase in the risk of developing T2D.

The pathway leading from uncomplicated simple steatosis to CVD events is not fully understood. It is known that hepatic steatosis can promote subclinical atherosclerosis via multiple traditional factors, such as hypertension, chronic inflammation, chronically decompensated diabetes, chronic kidney disease, hyperuricaemia, and increased epicardial fat. ${ }^{44}$

However, the main theoretical model thought to explain the promotion of atherogenesis in FLD is that of progression through hepatic lipotoxity with consequent apoptosis, inflammation and fibrosis. ${ }^{44}$ Fibrosing NASH results in hepatic production of prothrombogenic factors, fetuin-A and several lipid species, including free cholesterol, arachidonic acid and ceramides. Fetuin A inhibits ectopic calcifications, stimulates vascular inflammation and macrophage foam cell formation, and induces smooth muscle cell proliferation and collagen production. ${ }^{44}$ Free cholesterol, arachidonic acid, ceramides and other lipid species are thought to be linked with atherosclerotic plaque instability. ${ }^{44}$ These ultimately accelerate the development and progression of CVD in the natural course of atherosclerosis.

It is logical to expect that regression of FLD would be associated with reduced CMD risk when compared with stable disease. Altogether, 24 (4.8\%) of the subjects had a significant decrease in FLI. The significant decrease 
Table 3 (A, B) Association of FLI change with risk of incident CMD (B) after excluding men with high alcohol intake

\section{(A) 19 years from baseline}

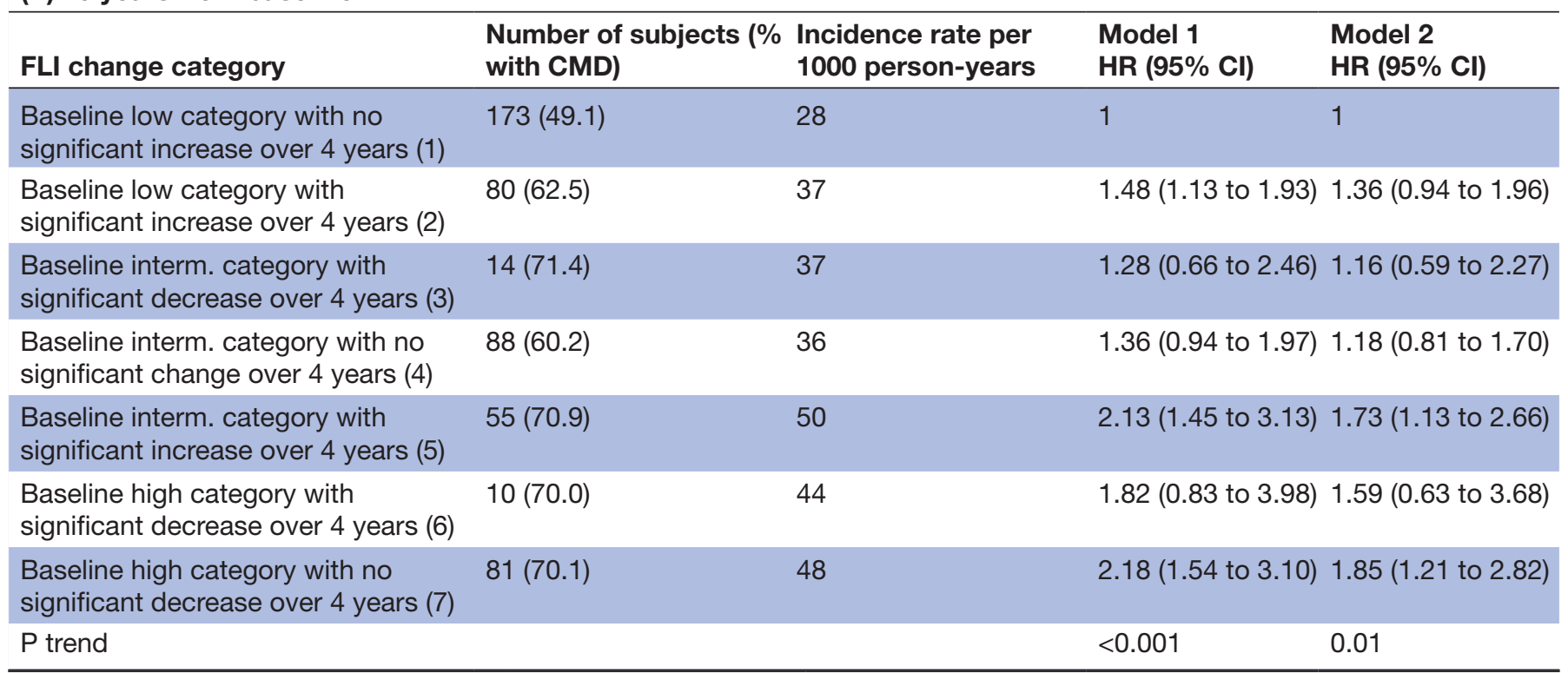

(B) 19 years from baseline

\begin{tabular}{|c|c|c|c|c|}
\hline FLI change category & $\begin{array}{l}\text { Number of subjects } \\
\text { (\% with CMD) }\end{array}$ & $\begin{array}{l}\text { Incidence rate per } \\
1000 \text { person-years }\end{array}$ & $\begin{array}{l}\text { Model } 1 \\
\text { HR }(95 \% \mathrm{CI})\end{array}$ & $\begin{array}{l}\text { Model } 2 \\
\text { HR }(95 \% \mathrm{Cl})\end{array}$ \\
\hline $\begin{array}{l}\text { Baseline low category with no } \\
\text { significant increase over } 4 \text { years (1) }\end{array}$ & 162 (51.2) & 29 & 1 & 1 \\
\hline $\begin{array}{l}\text { Baseline low category with significant } \\
\text { increase over } 4 \text { years (2) }\end{array}$ & $69(63.8)$ & 38 & 1.41 (0.98 to 2.01$)$ & $1.28(0.86$ to 1.90$)$ \\
\hline $\begin{array}{l}\text { Baseline interm. category with no } \\
\text { significant change over } 4 \text { years (4) }\end{array}$ & $79(55.7)$ & 33 & 1.19 (0.98 to 1.44$)$ & 1.03 (0.69 to 1.52$)$ \\
\hline $\begin{array}{l}\text { Baseline interm. category with } \\
\text { significant increase over } 4 \text { years (5) }\end{array}$ & $46(71.7)$ & 51 & 1.97 (1.30 to 2.97$)$ & 1.55 (0.98 to 2.45$)$ \\
\hline $\begin{array}{l}\text { Baseline high category with significant } \\
\text { decrease over } 4 \text { years (6) }\end{array}$ & $8(62.5)$ & 39 & 1.46 (0.92 to 2.32$)$ & $1.19(0.45$ to 3.13$)$ \\
\hline $\mathrm{P}$ trend & & & $<0.001$ & 0.048 \\
\hline
\end{tabular}

Model 1: FLI, age, examination date, baseline smoking pack-years, baseline alcohol consumption per week, baseline physical activity, baseline fruit-berry-vegetable consumption.

Model 2: model 1 plus fasting glucose, insulin, high-density lipoprotein, low-density lipoprotein, systolic blood pressure, diastolic blood pressure, $\mathrm{C}$ reactive protein, leucocyte count and thrombocyte count. $\mathrm{CMD}$, cardiometabolic disease; FLI, fatty liver index; interm, intermediate.

from high FLI was associated with lesser risk of incident T2D. We submit that the low number of subjects that had significant reduction in FLI over the 4 years and the resultant pattern of association observed precludes definitive statements about FLI decrease and risk of incident CVD. Nevertheless, the association of FLI increase with increased risk of CMD holds for CVD and T2D separately. It also holds even when men with high alcohol consumption were excluded, indicating that our findings are also applicable to NAFLD. Furthermore, the association was already evident by 10 years of follow-up.

\section{Study limitations and strengths}

First FLI, as a surrogate of fatty liver, does not distinguish between increased hepatic steatosis, progression of FLD to steatohepatitis and progression of FLD to hepatic fibrosis. Therefore, we are unable to differentiate the contribution of steatohepatitis and fibrosis to the observed association. 
Table 4 (A, B) Association of FLI change with 10-year risk of incident CMD (B) after excluding men with high alcohol intake

\section{(A) 14 years from baseline}

\begin{tabular}{|c|c|c|c|c|}
\hline FLI change category & $\begin{array}{l}\text { Number of } \\
\text { subjects (\% } \\
\text { with CMD) }\end{array}$ & $\begin{array}{l}\text { Incidence } \\
\text { rate per } 1000 \\
\text { person-years }\end{array}$ & $\begin{array}{l}\text { Model } 1 \\
\text { HR (95\% Cl) }\end{array}$ & $\begin{array}{l}\text { Model } 2 \\
\text { HR }(95 \% \mathrm{Cl})\end{array}$ \\
\hline $\begin{array}{l}\text { Baseline low category with no significant increase over } 4 \\
\text { years (1) }\end{array}$ & $173(22.5)$ & 18 & 1 & 1 \\
\hline $\begin{array}{l}\text { Baseline low category with significant increase over } 4 \\
\text { years (2) }\end{array}$ & $80(26.3)$ & 21 & $\begin{array}{l}1.21(0.92 \text { to } \\
1.59)\end{array}$ & $\begin{array}{l}1.08(0.62 \text { to } \\
1.86)\end{array}$ \\
\hline $\begin{array}{l}\text { Baseline interm. category with significant decrease over } 4 \\
\text { years (3) }\end{array}$ & $14(21.4)$ & 16 & $\begin{array}{l}0.85(0.30 \text { to } \\
2.40)\end{array}$ & $\begin{array}{l}0.85(0.26 \text { to } \\
2.77)\end{array}$ \\
\hline $\begin{array}{l}\text { Baseline interm. category with no significant change over } \\
4 \text { years (4) }\end{array}$ & $88(34.1)$ & 27 & $\begin{array}{l}1.47(0.97 \text { to } \\
2.25)\end{array}$ & $\begin{array}{l}1.19(0.71 \text { to } \\
1.98)\end{array}$ \\
\hline $\begin{array}{l}\text { Baseline interm. category with significant increase over } 4 \\
\text { years (5) }\end{array}$ & $55(45.5)$ & 41 & $\begin{array}{l}2.46(1.90 \text { to } \\
3.19)\end{array}$ & $\begin{array}{l}1.89(1.07 \text { to } \\
3.34)\end{array}$ \\
\hline $\begin{array}{l}\text { Baseline high category with significant decrease over } 4 \\
\text { years (6) }\end{array}$ & $10(40.0)$ & 34 & $\begin{array}{l}1.98(0.69 \text { to } \\
5.66)\end{array}$ & $\begin{array}{l}1.38(0.45 \text { to } \\
4.21)\end{array}$ \\
\hline $\begin{array}{l}\text { Baseline high category with no significant decrease over } \\
4 \text { years (7) }\end{array}$ & $81(43.2)$ & 39 & $\begin{array}{l}2.53(1.59 \text { to } \\
4.03)\end{array}$ & $\begin{array}{l}1.87(1.05 \text { to } \\
3.32)\end{array}$ \\
\hline $\mathrm{P}$ trend & & & $<0.001$ & 0.02 \\
\hline
\end{tabular}

(B) 14 years from baseline

\begin{tabular}{|c|c|c|c|c|}
\hline FLI change category & $\begin{array}{l}\text { Number of } \\
\text { subjects (\% } \\
\text { with CMD) }\end{array}$ & $\begin{array}{l}\text { Incidence } \\
\text { rate per } 1000 \\
\text { person-years }\end{array}$ & $\begin{array}{l}\text { Model } 1 \\
\text { HR }(95 \% \mathrm{Cl})\end{array}$ & $\begin{array}{l}\text { Model } 2 \\
\text { HR }(95 \% \mathrm{Cl})\end{array}$ \\
\hline $\begin{array}{l}\text { Baseline low category with no significant increase over } 4 \\
\text { years (1) }\end{array}$ & $162(24.1)$ & 19 & 1 & 1 \\
\hline $\begin{array}{l}\text { Baseline low category with significant increase over } 4 \\
\text { years ( } 2 \text { ) }\end{array}$ & 69 (27.5) & 22 & $\begin{array}{l}1.20(0.90 \text { to } \\
1.59)\end{array}$ & $\begin{array}{l}1.04(0.59 \text { to } \\
1.85)\end{array}$ \\
\hline $\begin{array}{l}\text { Baseline interm. category with significant decrease over } 4 \\
\text { years (3) }\end{array}$ & $11(27.3)$ & 21 & $\begin{array}{l}0.99(0.36 \text { to } \\
2.72)\end{array}$ & $\begin{array}{l}0.98(0.30 \text { to } \\
3.24)\end{array}$ \\
\hline $\begin{array}{l}\text { Baseline interm. category with no significant change over } \\
4 \text { years (4) }\end{array}$ & 79 (31.6) & 25 & $\begin{array}{l}1.32(0.78 \text { to } \\
2.22)\end{array}$ & $\begin{array}{l}1.10(0.64 \text { to } \\
1.88)\end{array}$ \\
\hline $\begin{array}{l}\text { Baseline interm. category with significant increase over } 4 \\
\text { years (5) }\end{array}$ & $46(45.7)$ & 42 & $\begin{array}{l}2.36(1.37 \text { to } \\
4.05)\end{array}$ & $\begin{array}{l}1.79(0.98 \text { to } \\
3.30)\end{array}$ \\
\hline $\begin{array}{l}\text { Baseline high category with significant decrease over } 4 \\
\text { years (6) }\end{array}$ & $8(37.5)$ & 32 & $\begin{array}{l}1.76(0.56 \text { to } \\
5.78)\end{array}$ & $\begin{array}{l}1.22(0.34 \text { to } \\
4.34)\end{array}$ \\
\hline $\begin{array}{l}\text { Baseline high category with no significant decrease over } \\
4 \text { years (7) }\end{array}$ & $58(43.1)$ & 39 & $\begin{array}{l}2.43(1.46 \text { to } \\
4.06)\end{array}$ & $\begin{array}{l}1.78(0.94 \text { to } \\
3.36)\end{array}$ \\
\hline $\mathrm{P}$ trend & & & $<0.001$ & 0.05 \\
\hline
\end{tabular}

Model 1: FLI, age, examination date, baseline smoking pack-years, baseline alcohol consumption per week, baseline physical activity, baseline fruit-berry-vegetable consumption.

Model 2: model 1 plus fasting glucose, insulin, high-density lipoprotein, low-density lipoprotein, systolic blood pressure, diastolic blood pressure, $\mathrm{C}$ reactive protein, leucocyte count and thrombocyte count.

$\mathrm{CMD}$, cardiometabolic disease; FLI, fatty liver index; interm, intermediate.

However, since FLI also correlates with degree of NASH and degree of fibrosis, higher degrees of inflammation or fibrosis results in higher FLI among individuals with similar histological degrees of steatosis. ${ }^{24}$ Therefore, the significant FLI increases observed do not represent increases in quantification of steatosis only, but generally represent a combination of increased steatosis, increased steatohepatitis or increased fibrosis. ${ }^{24}$ Another limitation of the study is that the hepatitis B and hepatitis C statuses of the subjects were not established at baseline. However, the prevalence rates of hepatitis $\mathrm{B}^{46}$ and hepatitis $\mathrm{C}^{47}$ have remained low in the Finnish population. Also, our study population comprised of men only. There are reports that suggest that lower FLI cut-off values may apply to women. ${ }^{48}$ We are unable to explore the influence of gender on the association of FLI increase with increased risk of incident CMD. Nevertheless, Bedogni et al concluded that the influence of gender in FLI is related 
to insulin and skinfold thickness and probably insignificant. ${ }^{22}$ Furthermore, conducting the study on a cohort of men removes the bias that may be associated with hormonal changes in women.

The strength of our study lies in the prospective design. With this, we are able to demonstrate the temporal association of the increases in FLI, with incident occurrence of CMD (T2D and CMD). Although follow-up was largely unstructured, for all the subjects, occurrence of disease outcomes could be detected through the disease registers. Therefore, there were no losses during follow-up with respect to the outcome.

Our findings further highlight areas that need to be studied further. Compared with subjects without disease regression, the lower risk of incident CMDs (and incident CVDs) associated with significant regression of FLI-assessed, Ultrasound scan-assessed or MRI-assessed FLD needs additional studies.

\section{Clinical implications}

Clinicians managing patients with internal diseases now need to be aware of changing fatty liver status over time. Persons with significantly increased FLI, from previously normal or intermediate FLI, should be further evaluated for FLD, and if found with FLD, they should be evaluated and monitored for CMD. In such persons, appropriate preventive or treatment measures should be instituted to improve their prognoses.

\section{CONCLUSION}

Our data suggest that development or progression of FLD is associated with an increase in risk of incident CMD. Those who progressed over the 4 years from low (normal) baseline FLI category already had risk comparable with that of persons at intermediate baseline FLI category. Those who progressed over the 4 years from intermediate FLI category at baseline had risk comparable with that of persons who maintained high FLI category both at baseline and at follow-up. Therefore, in clinical practice, persons with significantly increasing FLI should be further evaluated for new or progressive FLD to establish hepatic steatosis, presence of steatohepatitis and degree of fibrosis. Such persons should be evaluated, monitored and managed to prevent development of CMD.

Contributors 000 and T-PT conceived the study. 000 and T-PT designed the study. 000 performed the statistical analyses. 000 wrote the first draft of the manuscript. 000, JKV, JP, PM and T-PT contributed to the development of the manuscript and reviewed the final draft of the manuscript.

Funding The Kuopio Ischaemic Heart Disease Risk Factor Study baseline and fourth-year examinations were funded by Academy of Finland, grants 41471, 1041086 and 2041022.

Competing interests None declared.

Patient consent for publication Not required.

Ethics approval The KIHD study was approved by the Research Ethics Committee of the Kuopio University Hospital with approval number 143/97 and the subjects gave their written consent.

Provenance and peer review Not commissioned; externally peer reviewed.
Data availability statement No data are available.

Open access This is an open access article distributed in accordance with the Creative Commons Attribution Non Commercial (CC BY-NC 4.0) license, which permits others to distribute, remix, adapt, build upon this work non-commercially, and license their derivative works on different terms, provided the original work is properly cited, appropriate credit is given, any changes made indicated, and the use is non-commercial. See: http://creativecommons.org/licenses/by-nc/4.0/.

\section{REFERENCES}

1. Younossi ZM. Non-Alcoholic fatty liver disease-a global public health perspective. J Hepatol 2018.

2. Rehm J, Samokhvalov AV, Shield KD. Global burden of alcoholic liver diseases. J Hepatol 2013;59:160-8.

3. Alexander M, Loomis AK, Fairburn-Beech J, et al. Real-World data reveal a diagnostic gap in non-alcoholic fatty liver disease. BMC Med 2018;16:130.

4. Vernon G, Baranova A, Younossi ZM. Systematic review: the epidemiology and natural history of non-alcoholic fatty liver disease and non-alcoholic steatohepatitis in adults. Aliment Pharmacol Ther 2011;34:274-85.

5. Chacko KR, Reinus J. Spectrum of alcoholic liver disease. Clin Liver Dis 2016;20:419-27.

6. Pierantonelli I, Svegliati-Baroni G. Nonalcoholic fatty liver disease: basic pathogenetic mechanisms in the progression from NAFLD to NASH. Transplantation 2019;103:e1-13.

7. Hagström H, Elfwén O, Hultcrantz R, et al. Steatohepatitis is not associated with an increased risk for fibrosis progression in nonalcoholic fatty liver disease. Gastroenterol Res Pract 2018;2018:1-7.

8. Ekstedt M, Hagström H, Nasr P, et al. Fibrosis stage is the strongest predictor for disease-specific mortality in NAFLD after up to 33 years of follow-up. Hepatology 2015;61:1547-54.

9. Pelusi S, Cespiati A, Rametta R, et al. Prevalence and risk factors of significant fibrosis in patients with nonalcoholic fatty liver without steatohepatitis. Clin Gastroenterol Hepatol 2019. doi:10.1016/j. cgh.2019.01.027. [Epub ahead of print: 29 Jan 2019].

10. Chang Y, Ryu S, Sung KC, et al. Alcoholic and non-alcoholic fatty liver disease and associations with coronary artery calcification: evidence from the Kangbuk Samsung health study. Gut 2018.

11. Younossi Z, Henry L. Contribution of Alcoholic and Nonalcoholic Fatty Liver Disease to the Burden of Liver-Related Morbidity and Mortality. Gastroenterology 2016;150:1778-85.

12. Faasse $\mathrm{S}$, Braun $\mathrm{H}$, Vos M. The role of NAFLD in cardiometabolic disease: an update. F1000Res 2018;7.

13. Ballestri S, Zona S, Targher G, et al. Nonalcoholic fatty liver disease is associated with an almost twofold increased risk of incident type 2 diabetes and metabolic syndrome. Evidence from a systematic review and meta-analysis. J Gastroenterol Hepatol 2016;31:936-44.

14. Targher G, Byrne CD, Lonardo A, et al. Non-Alcoholic fatty liver disease and risk of incident cardiovascular disease: a meta-analysis. $J$ Hepatol 2016;65:589-600.

15. Younossi ZM, Koenig AB, Abdelatif D, et al. Global epidemiology of nonalcoholic fatty liver disease-meta-analytic assessment of prevalence, incidence, and outcomes. Hepatology 2016;64:73-84.

16. Bataller R, Arteel GE, Moreno C, et al. Alcohol-Related liver disease: time for action. $J$ Hepatol 2019;70:221-2.

17. Dong $F$, Zhang $Y$, Huang $Y$, et al. Long-Term lifestyle interventions in middle-aged and elderly men with nonalcoholic fatty liver disease: a randomized controlled trial. Sci Rep 2016;6:36783.

18. Dixon JB, Bhathal PS, O'Brien PE. Weight loss and nonalcoholic fatty liver disease: falls in gamma-glutamyl transferase concentrations are associated with histologic improvement. Obes Surg 2006;16:1278-86.

19. Parker BM, Wu J, You J, et al. Reversal of fibrosis in patients with nonalcoholic steatohepatosis after gastric bypass surgery. BMC Obes 2017;4.

20. Guo F, Moellering DR, Garvey WT. The progression of cardiometabolic disease: validation of a new cardiometabolic disease staging system applicable to obesity. Obesity 2014;22:110-8.

21. Pappachan JM, Babu S, Krishnan B, et al. Non-Alcoholic fatty liver disease: a clinical update. J Clin Trans/ Hepatol 2017;5:384.

22. Bedogni G, Bellentani S, Miglioli L, et al. The fatty liver index: a simple and accurate predictor of hepatic steatosis in the general population. BMC Gastroenterol 2006;6:33.

23. Chen L-W, Huang P-R, Chien C-H, et al. A community-based study on the application of fatty liver index in screening subjects with nonalcoholic fatty liver disease. J Formos Med Assoc 2019. 
24. Fedchuk L, Nascimbeni F, Pais R, et al. Performance and limitations of steatosis biomarkers in patients with nonalcoholic fatty liver disease. Aliment Pharmacol Ther 2014;40:1209-22.

25. Hartleb M, Barański K, Zejda J, et al. Non-Alcoholic fatty liver and advanced fibrosis in the elderly: results from a community-based Polish survey. Liver Int 2017;37:1706-14.

26. Olubamwo OO, Virtanen JK, Voutilainen A, et al. Association of fatty liver index with the risk of incident cardiovascular disease and acute myocardial infarction. Eur J Gastroenterol Hepatol 2018;30:1047-54.

27. Jäger S, Jacobs S, Kröger J, et al. Association between the fatty live index and risk of type 2 diabetes in the EPIC-Potsdam study. PLoS One 2015;10:e0124749.

28. Salonen JT. Is there a continuing need for longitudinal epidemiologic research? the Kuopio ischaemic heart disease risk factor study. Ann Clin Res 1988;20:46-50.

29. Salonen JT, Seppänen K, Nyyssönen K, et al. Intake of mercury from fish, lipid peroxidation, and the risk of myocardial infarction and coronary, cardiovascular, and any death in eastern Finnish men. Circulation 1995;91:645-55.

30. Räsänen J, Kauhanen J, Lakka TA, et al. Religious affiliation and allcause mortality: a prospective population study in middle-aged men in eastern Finland. Int J Epidemiol 1996;25:1244-9.

31. Laukkanen JA, Pukkala E, Rauramaa R, et al. Cardiorespiratory fitness, lifestyle factors and cancer risk and mortality in Finnish men. Eur J Cancer 2010;46:355-63.

32. Willenbring ML, Massey SH, Gardner MB. Helping patients who drink too much: an evidence-based guide for primary care clinicians. Am Fam Physician 2009;80:44-50.

33. McGuire S. U.S. Department of agriculture and U.S. Department of health and human services, Dietary Guidelines for Americans, 2010. 7th edition, Washington, DC: U.S. Government Printing Office, January 2011. Adv Nutr 2011;2:293-4.

34. Virtanen JK, Mursu J, Tuomainen T-P, et al. Dietary fatty acids and risk of coronary heart disease in men: the Kuopio ischemic heart disease risk factor study. Arterioscler Thromb Vasc Biol 2014;34:2679-87.

35. Kauhanen J, Kaplan GA, Goldberg DE, et al. Pattern of alcohol drinking and progression of atherosclerosis. Arterioscler Thromb Vasc Biol 1999;19:3001-6.

36. Alberti K. International diabetes Federation Task force on epidemiology and prevention; Hational heart, lung, and blood Institute; American heart association; Wo. Circulation 2009;120:1640-5.

37. Cheema JR. Some general guidelines for choosing missing data handling methods in educational research. J Mod App/ Stat Meth 2014;13:53-75.

38. Fawehinmi TO, llomäki J, Voutilainen S, et al. Alcohol consumption and dietary patterns: the FinDrink study. PLoS One 2012;7:e38607.

39. Sung K-C, Wild SH, Byrne CD. Resolution of fatty liver and risk of incident diabetes. J Clin Endocrinol Metab 2013;98:3637-43.

40. Arulanandan A, Ang B, Bettencourt R, et al. Association between quantity of liver fat and cardiovascular risk in patients with nonalcoholic fatty liver disease independent of nonalcoholic steatohepatitis. Clin Gastroenterol Hepatol 2015;13:1513-20.

41. Valenti L, Bugianesi E, Pajvani U, et al. Nonalcoholic fatty liver disease: cause or consequence of type 2 diabetes? Liver Int 2016;36:1563-79.

42. Jiang ZG, de Boer $\mathrm{IH}$, Mackey $\mathrm{RH}$, et al. Associations of insulin resistance, inflammation and liver synthetic function with very lowdensity lipoprotein: the cardiovascular health study. Metabolism 2016;65:92-9.

43. Targher G, Byrne CD. Clinical review: nonalcoholic fatty liver disease: a novel cardiometabolic risk factor for type 2 diabetes and its complications. J Clin Endocrinol Metab 2013;98:483-95.

44. Lonardo A, Nascimbeni F, Mantovani A, et al. Hypertension, diabetes, atherosclerosis and NASH: cause or consequence? J Hepatol 2018;68:335-52.

45. Alkhouri N, Tamimi TA-R, Yerian L, et al. The inflamed liver and atherosclerosis: a link between histologic severity of nonalcoholic fatty liver disease and increased cardiovascular risk. Dig Dis Sci 2010;55:2644-50.

46. Karvonen T, Auranen K, Kuusi M, et al. Epidemiology of hepatitis B infection in Finland: implications for immunisation policy. Vaccine 2017;35:412-8.

47. Safreed-Harmon K, Hetherington KL, Aleman S, et al. Policy responses to hepatitis $C$ in the Nordic countries: gaps and discrepant reporting in the Hep-Nordic study. PLoS One 2018;13:e0190146.

48. Yang B-L, Wu W-C, Fang K-C, et al. External validation of fatty liver index for identifying ultrasonographic fatty liver in a large-scale cross-sectional study in Taiwan. PLoS One 2015;10:e0120443. 